\title{
Research on Futures Price Volatility Transmission Effect: Evidence from the CBOT and DCE Soybean Futures
}

\author{
Quan Gu*, Xinghui Lei \\ School of Economics and Management, Tongji University, Shanghai 200092, China \\ *11guquan@tongji.edu.cn
}

Keywords: Futures markets, Price Co-movement, Autoregressive Model

\begin{abstract}
Based on the principle of financial market prices of infection and linkage, the Markov state transition autoregressive model is used to make a comparative study on the Dalian Commodity Exchange and the Chicago Board of Trade soybean futures price linkage relationship. Research model can be well portrayed between the two futures market's price discovery contributions, and verify the linkage relationship of the two market's futures prices.
\end{abstract}

\section{Introduction}

Along with rapid economic development, China has gradually increased dependence on external resources by international market. Overseas resources have become an important foundation for the sustainable development of China's national economy. Beginning in 1996, China's soybean imports surged, the volume of imports rose from 0.58 million tons to 95.54 million tons in 2017. Volatility of soybean prices in the international market price risk is increasing, the world's major soybean trading nation in the increasingly fierce competition for soybean pricing. So as one of the major producing countries and the largest importer of soybean, what role does China actually play in the world soybean market pricing? Soybean international trade price is determined by the soybean futures market, so to examine the pricing position is to study the price relationship between domestic soybean futures market and the international soybean futures market.

In the related studies, the study of price transfer of many commodity futures draws different conclusions $[1,2,3,5]$. Previous studies may have the following limitations: the basic point of view from the research models are based on long-term relationship, this method is simple and intuitive expression of the relationship between the object. But the futures market have a variety of factors to each other on effect of complex systems [4,6], the model also over-simplifies the problem. The linear regression method from the methodology, used in most early research literature, due to causal relationship between the futures market interaction, and interaction of complex relationships, it is very difficult to determine the causal relationship between the variables.

This Research focuses on soybean futures which are listed on Dalian Commodity Exchange(DCE) and Chicago Board of Trade(CBOT). We examine the relationship between the two markets futures price volatility transmission, and then conclude China's pricing power in the soybean market. In this paper, we use Markov state transition autoregressive model to measure and distinguish the state of futures market volatility. Two states use single variable MS (p)-AR (q) model, the market volatility during the six market samples in the status area is divided into the high volatility and low volatility. The contribution of this paper is to use a Markov state transition autoregressive model to investigate the price relationship between China and the U.S. soybean futures market and both futures market price discovery contribution.

\section{Method}

We describe the economic cycle of expansion and contraction of the first Markov state transition, and the nature of the introduction to the form of time series model constitutes a nonlinear time series model as follows: 


$$
\mathrm{Y}_{\mathrm{t}}=\alpha\left(\mathrm{S}_{\mathrm{t}}\right)+\sum_{\mathrm{i}=1}^{\mathrm{p}} \beta_{\mathrm{i}} \mathrm{Y}_{\mathrm{t}-\mathrm{i}}+\varepsilon_{\mathrm{t}}
$$

This is a $Y_{t}$ p-order autoregressive process, which cannot be observed state, variable $S_{t}$ is a value space Markov chain $\{1,2, \mathrm{~m}\}$, which is also in $\mathrm{m}$ state. The random error satisfy normal distribution $\varepsilon_{\mathrm{t}} \sim \mathrm{N}\left(0, \sigma^{2}\right)$.To illustrate the meaning of the model, it can be said that a modified form for the conditional mean:

$$
\mathrm{Y}_{\mathrm{t}}-\mu\left(\mathrm{S}_{\mathrm{t}}\right)=\sum_{\mathrm{i}=1}^{\mathrm{p}} \beta_{\mathrm{i}}\left[\mathrm{Y}_{\mathrm{t}-\mathrm{i}}-\mu\left(\mathrm{S}_{\mathrm{t}-\mathrm{i}}\right)\right]+\varepsilon_{\mathrm{t}}
$$

The constraint of state parameter variable conversion is:

$$
\alpha\left(S_{t}\right)=\mu\left(S_{t}\right)-\sum_{i=1}^{p} \beta_{i} \mu\left(S_{t-i}\right)
$$

An objective description of the different state of fluctuation, the above model to be expanded, joined the state variable $S_{t}$ in item $\varepsilon_{t}$. Assuming that $\varepsilon_{p}\left(S_{t}\right) \sim \operatorname{NID}\left(0, \sum\left(S_{t}\right)\right)$, the model variance of the residuals with the transfer of the state; the fluctuations in the form of the different states are better able to reflect futures market. Determination of the number of states can take advantage of the standardized LR test. Due to research purposes progressive $\chi^{2}(q)$ distribution of the LR test statistic value, we select the two states, $m=2$ and $m=1$, assuming $m=1$ that the market is the high volatility phase, $\mathrm{m}=2$ the market is low fluctuations in stage. The corresponding variance: $\sigma^{2}\left(S_{1}\right)>\sigma^{2}\left(S_{2}\right)$. Probability of the $S_{t}$ state value:

$$
p_{i j}=P\left(S_{t}=j \mid S_{t-1}=i, S_{t-1}=m, \ldots, y_{t}, y_{t-1}, \ldots\right)
$$

It can be seen from Eq(6) obey the Markov state transition process, the probability values of the state $S_{t}$ only move with $S_{t-1}$ status. Transition probability matrix of the variables $S_{1}$ is:

$$
\mathrm{P}=\left(\mathrm{P}_{\mathrm{r}}\left(\mathrm{S}_{\mathrm{t}}=\mathrm{j} \mid \mathrm{S}_{\mathrm{t}-1}=\mathrm{i}\right)\right)_{2 \times 2}=\left(\begin{array}{ll}
\mathrm{p}_{11} & \mathrm{p}_{12} \\
\mathrm{p}_{21} & \mathrm{p}_{22}
\end{array}\right)=\left(\begin{array}{cc}
\mathrm{p} & 1-\mathrm{q} \\
1-\mathrm{p} & \mathrm{q}
\end{array}\right)
$$

$\mathrm{P}$ as a continuous two state transition probabilities which is low volatility phase; $\mathrm{q}$ said for two state transition probabilities is high volatility phase. State variables $S_{1}$ is not observed, so only through the calculation of state variables in different periods of the values of probability is to determine the values of $\mathrm{S}_{1}$. Estimated the probability of $\mathrm{S}_{1}$ value can be divided into three types: predicted probabilities, filtered probabilities and smoothed probabilities. Predicted probability is to the value of probability of the available information deduced $(t-1)$ during the state variables $S_{1}$ denoted by $\mathrm{P}\left(\mathrm{S}_{\mathrm{i}} \mid \Psi_{\mathrm{i}-1}\right)\left(\Psi_{\mathrm{i}-1}\right.$ indicated that the available information set $\left.\left\{\mathrm{y}_{\mathrm{i}-1}, \mathrm{y}_{\mathrm{i}-2} \ldots\right\}\right)$ filtered probabilities is the use of the information available to the period t deduced the probability $P\left(S_{i} \mid \Psi_{i}\right)$. Actually filtered probabilities in the new data are to predict the probability $\mathrm{P}\left(\mathrm{S}_{\mathrm{i}} \mid \Psi_{\mathrm{i}-1}\right)$ correction; smoothed probabilities are used to the full sample information $\Psi_{\mathrm{T}}$ derivation of $S_{t}$ probability. In a two-state conditions, the maximum likelihood estimation smooth probability iterative formula:

$$
\mathrm{P}_{\mathrm{r}}\left(\mathrm{S}_{\mathrm{t}}=\mathrm{j} \mid \Psi_{\mathrm{T}}\right)=\sum_{\mathrm{i}=1}^{2} \mathrm{P}_{\mathrm{r}}\left(\mathrm{S}_{\mathrm{t}}=\mathrm{j}, \mathrm{S}_{\mathrm{t}+1}=\mathrm{i} \mid \Psi_{\mathrm{T}}\right)=\sum_{\mathrm{i}=1}^{2} \frac{\mathrm{P}_{\mathrm{r}}\left(\mathrm{S}_{\mathrm{t}-1}=\mathrm{i} \mid \Psi_{\mathrm{T}}\right) \times \mathrm{P}_{\mathrm{r}}\left(\mathrm{S}_{\mathrm{t}+1}=\mathrm{j} \mid \Psi_{\mathrm{T}}\right) \times \mathrm{P}_{\mathrm{r}}\left(\mathrm{S}_{\mathrm{t}+1}=\mathrm{i} \mid \mathrm{S}_{\mathrm{t}}=\mathrm{j}\right)}{\mathrm{P}_{\mathrm{r}}\left(\mathrm{S}_{\mathrm{t}-1}=\mathrm{i} \mid \Psi_{\mathrm{T}}\right)}
$$

According to the smoothed probability of the above iteration formula, we can calculate the smoothed probability of latent state variables in the entire sample range of $S_{t}$ values, range state can be divided in accordance with this smooth probability. The lag order of the model $\mathrm{y}_{\mathrm{t}}$ can use the AIC or SC guidelines to determine. The model estimated using the EM algorithm based on maximum likelihood estimation, finites number of iterations, and parameter maximum likelihood estimation.

\section{Results}

This paper focuses on the DCE and CBOT of soybean, soybean meal and soybean oil futures daily closing price. The sample interval is January 1, 2013 to December 31, 2016. DCE and CBOT Soy product futures price data were derived from the respective statistical database of the 
Exchange's website.

Table1 MS (p) - AR (q) Model Estimation Results

\begin{tabular}{llllllll}
\hline & \multicolumn{3}{c}{ State 1} & \multicolumn{3}{c}{ State 2} & Log \\
\cline { 2 - 7 } & \multicolumn{1}{c}{$\mu_{1}$} & \multicolumn{1}{c}{$\sigma_{1}$} & \multicolumn{1}{c}{$\beta_{1}$} & \multicolumn{1}{c}{$\mu_{2}$} & \multicolumn{1}{c}{$\sigma_{2}$} & \multicolumn{1}{c}{$\beta_{2}$} & likelihood \\
\cline { 2 - 7 } DCE & -0.0038 & 0.0025 & -0.0214 & 0.0027 & 0.321 & -0.0547 & 1845.2 \\
Soybean & $(0.0014)$ & $(0.0156)$ & $(0.0157)$ & $(0.0041)$ & $(0.0217)$ & $(0.0415)$ & \\
DCE & -0.0012 & 0.0078 & -0.0265 & -0.0215 & 0.0741 & -0.451 & 1984.7 \\
Soymeal & $(0.1245)$ & $(0.0154)$ & $(0.0124)$ & $(0.0074)$ & $(0.0015)$ & $(0.1024)$ & \\
DCE & 0.0021 & 0.0024 & 0.0004 & 0.1428 & 0.0741 & -0.0155 & 1198.1 \\
Soyoil & $(0.0032)$ & $(0.1421)$ & $(0.1245)$ & $(0.0067)$ & $(0.1247)$ & $(0.0148)$ & \\
CBOT & 0.0002 & 0.0014 & -0.0032 & 0.0049 & -0.098 & 0.0012 & 2421.5 \\
Soybean & $(0.0056)$ & $(0.0014)$ & $(0.1264)$ & $(0.1143)$ & $(0.0002)$ & $(0.0087)$ & \\
CBOT & -0.194 & -0.0028 & 0.0021 & 0.0035 & -0.1001 & 0.0008 & 1254.9 \\
Soymeal & $(0.0023)$ & $(0.0052)$ & $(0.1124)$ & $(0.0009)$ & $(0.1072)$ & $(0.0025)$ & \\
CBOT & 0.1141 & -0.0021 & 0.0247 & 0.0021 & -0.0006 & 0.1047 & 2215.2 \\
Soyoil & $(0.1021)$ & $(0.0019)$ & $(0.0004)$ & $(0.0034)$ & $(0.0231)$ & $(0.0043)$ & \\
\hline
\end{tabular}

From the model estimation results, we get the duration and value of the probability of high volatility in the duration and value of probability. Market volatility in the high volatility phase sequence is significantly higher than the low volatility, and the mean is greater than the mean of the low volatility phase [7-8]. Comparing similarities and differences between DCE and CBOT volatility, it gives the trajectory of the value of smoothed probabilities, in each state within the range of samples of the various markets. From Table1 we could see that the values of the high volatility state, there is no obvious state transition characteristics, market volatility has been relatively flat. We could also conclude that the high volatility state is very clear, and the interval of high volatility state patchwork, market volatility state transition, indicating a level of fluctuations in the transfer frequency faster market, the market is very active.

\section{Conclusion}

This paper shows that there is a certain correlation effect between the soybean futures price volatility in the DCE market and the CBOT market. The correlation effect between soybean oil and soybean meal is greater than that of soybean. Since the DCE soybean futures is non-genetically modified soybeans, and the CBOT soybean futures is genetically modified soybeans, the difference in the commodity causes the price-related effect to weaken. This empirical study shows that CBOT soybean futures have greater impact on DCE, and China's soybean pricing power is still weak. At the same time, this study verifies that both futures markets have alternating high and low volatility, and there is a phenomenon of price state transition. Future studies can be further explored using vector autoregressive models.

\section{References}

[1] Streeter, D. H., \& Tomek, W. G. (2010). Variability in soybean futures prices: an integrated framework. Journal of Futures Markets, 12(6), 705-728.

[2] Zhao, Y., \& Chunjie, A. Q. (2010). Is chinese soybean futures market efficient? A research based on event studies. Economic Review.

[3] Liyan Han, Rong Liang, \& Ke Tang. (2013). Cross-market soybean futures price discovery: does the dalian commodity exchange affect the chicago board of trade?. Quantitative Finance, 13(4), 613-626.

[4] Mark E. Holder, R. Daniel Pace, \& Michael J. Tomas III. (2010). Complements or substitutes? Equivalent futures contract markets-the case of corn and soybean futures on u.s. and japanese 
exchanges. Journal of Futures Markets, 22(4), 355-370.

[5] Turner, S. C., Houston, J. E., \& Shepherd, T. L. (2010). Supplementary information and markov processes in soybean futures trading. Journal of Futures Markets, 12(1), 61-74.

[6] Turner, S. C., \& Shepherd, T. L. (1992). Markov processes in soybean futures trading. Journal of Futures Markets, 12(1), 61-74.

[7] He, L. Y., \& Wang, R. (2011). A tale of two markets: who can represent the soybean futures markets in China. African Journal of Business Management, 5(3), 826-832.

[8] Li, C., \& Hayes, D. J. (2017). Price discovery on the international soybean futures markets: a threshold co-integration approach. Journal of Futures Markets, 37(1). 